\title{
Nursing students' resilience in response to stress related to the COVID-19 pandemic
}

\author{
Joset E. Brown* Persephone Vargas \\ William Paterson University, New Jersey, USA
}

Received: June 25, 2021

DOI: $10.5430 /$ jnep.v12n1p34
Accepted: August 4, 2021

URL: https://doi.org/10.5430/jnep.v12n1p34

\begin{abstract}
Background and purpose: The recent consequences of the COVID 19 pandemic thrust students into unfamiliar learning environments creating an additional stressor to their personal and academic lives. The purpose of this study was to explore the perceived level of stress, resilience, and coping mechanisms of the nursing students facing the challenges associated with transitioning to a virtual instructional platform during the COVID-19 pandemic.

Methods: Design: The study utilized a cross-sectional design. Using Qualtrics, electronic surveys were distributed to all nursing students in the undergraduate and graduate programs. The study measures used were: Connor Davidson-Resilience Scale and Perceived Stress Scale. Three open-ended questions were included in the survey to identify stressors and coping strategies. SPSS was used to analyze the data using descriptive statistics and correlational analyses. Thematic analysis was used to analyze the answers to the open-ended questions.

Results: A total of 148 students completed the survey. Using the Perceived Stress Scale, the undergraduate nursing students had a higher mean than the graduate students $(p<.05)$, indicating that the undergraduate students had a higher stress level. Using the Connor Davidson-Resilience Scale, the graduate nursing students had a higher resilience level than the undergraduate students $(p$ $<.005$ ), indicating that the graduate students had more resilience than the undergraduate students. Recurrent stressors and coping strategies were identified by the participants.

Conclusions: The study provides a better understanding of nursing students' stress and resilience levels in response to significant unexpected occurrences impacting academic life. Strategies and interventions can be implemented to promote students' resilience and improve their well-being during high-level stressful situations.
\end{abstract}

Key Words: Resilience, Stress, COVID-19, Nursing student

\section{INTRODUCTION}

Hans Selye (1975) defines stress as 'the non-specific response of the body to any demand placed upon it regardless of the stressor". ${ }^{[1]}$ Stress is pervasive and all-encompassing and can result from, and simultaneously affect all areas of an individual's life. ${ }^{[2]}$ There is a myriad of effects resulting from exposure to stress during the course of scholarship for nursing students. Stress decreases resilience, optimal functioning and contributes to decreased academic performance. ${ }^{[3,4]}$

\subsection{Stress among nursing students}

Multiple factors contribute to stress that impacts a student's life both personally and academically. When compared to undergraduates in other programs, nursing students experience higher levels of stress and stress-related responses. ${ }^{[5,6]}$ Contributors to nursing student stress includes clinical place-

*Correspondence: Joset E. Brown; Email: brownj127@wpunj.edu; Address: William Paterson University, New Jersey, USA. 
ments, the intensity of the curriculum, balancing their personal life and academia, and exposure to grief, death, critical illness and ethical dilemmas during clinical rotations. ${ }^{[2,7-9]}$ Though individual factors contribute to stress, the clinical environment is reported as the main extrinsic predictor for stress for nursing students. ${ }^{[2]}$ For nursing students in particular, increased stress levels negatively impact their ability to critically think, impair decision-making, and ultimately decreases academic performance and inhibits success. ${ }^{[2,6]}$

In general, graduate students in health sciences have high stress levels. These students have reported stress impacting their physical health, relationships, academic performance, and mental health. ${ }^{[10]}$ Among graduate nursing students, sources of stress include financial, role responsibilities, competing obligations, academic demands, and clinical practicum. ${ }^{[11]}$ Further, the emotional and mental health of university students is regarded to be impacted negatively due to the drastic isolation measures applied due to the COVID19 pandemic. ${ }^{[12]}$

\subsection{Resilience}

Disciplines such as science (nursing and medicine), business, and psychology have all used the concept of resilience in their research and practice. ${ }^{[13]}$ Resilience is defined as the ability of adults in otherwise normal circumstances, who were exposed to an isolated and potentially highly disruptive event, to maintain and return to relatively stable and healthy levels of psychological and physical functioning and the capacity for generative experiences and positive emotions. ${ }^{[7,13-15]}$ Resilience fosters one's ability to adapt and develop positive coping strategies. ${ }^{[16]}$

According to Herrman et al., ${ }^{[13]}$ resilience is a dynamic process that can be influenced by the environment, external factors, the individual, and the outcome; however, a requirement for the development of resilience is the presence of an adverse or traumatic event. First, this event could place an individual at risk for compromising their ability to cope and overcome stressors. Secondly, once an adverse event occurs or is present, it must be interpreted as physically and or psychologically traumatic. Finally, depending on their response to these stressors, individuals might develop protective factors which can decrease both the effects and adverse reactions to risk, ${ }^{[17]}$ thereby developing resilience.

There is an abundance of literature on stress for the nursing student; however, there is a paucity regarding their resilience in response to stress; and more specifically the response to stress related to a pandemic. In addition to psychological stress, students enrolled in health-related fields of study are likely to be impacted professionally by the effects of the
COVID-19 pandemic. ${ }^{[18]}$ As the effects of stress are notably so pervasive and deleterious it is imperative that we explore and determine ways to enhance and support their resilience.

\subsection{Background}

In March 2020, New Jersey (NJ) declared a state of emergency due to the COVID-19 pandemic creating a logistical challenge to schools nationally. In response, schools in NJ abruptly transitioned from a traditional face-to-face format to a virtual format. The events associated with the COVID-19 pandemic thrust students into unfamiliar virtual learning environments creating an additional stressor to their academic requirements. The transition to a virtual platform mid-semester profoundly impacted nursing education, particularly content delivery methods and the inability to have clinical experience reinforce theoretical content. There is a concern for the student's ability to adjust to this new academic environment while fulfilling their educational requirements. The purpose of this study was to explore stress, resilience, and coping mechanisms among nursing students facing the challenges associated with transitioning to a virtual instructional platform during the COVID-19 pandemic.

The study aims to answer the following questions:

1) What is the perceived level of stress and level of resilience among nursing students?

2) Is there a relationship between the perceived level of stress and the perceived resilience of the students?

3) Is there a relationship between sociodemographic variables such as age, race, gender and educational background and the students' perceived stress and resilience?

4) What are the stressors and the coping strategies of nursing students?

\section{Methodology}

\subsection{Research design and participants}

The study was conducted in a public university in northern NJ using a descriptive cross-sectional design. The study utilized a convenience sample of nursing students currently enrolled in the undergraduate or graduate program. The sample consisted of 148 nursing students, in the undergraduate and graduate level. Initially, 150 students responded to the survey, of these, 148 completed the survey, giving a response rate of $98.6 \%$.

\subsection{Procedure}

Institutional Review Board approval was obtained prior to the start of the study. Permission to utilize both instruments was obtained as part of the IRB approval process. The survey was conducted electronically using Qualtrics and was distributed to all nursing students between May 2020 - June 
2020. All surveys were conducted anonymously. To ensure anonymity and confidentiality, identifying personal information were not obtained. The informed consent appeared on the first page of the survey informing the participant of the purpose of the study. The participant had to select "Yes, proceed to survey" to provide consent and gain access to the questionnaire. Those who do not wish to proceed with the survey were able to select "No, exit this survey" and were directed to the exit page. No compensation was provided for participating in the survey.

\subsection{Instruments}

The Perceived Stress Scale (PSS) is an instrument used to measure the perception of stress which was amended to create the current PSS-10, a 10-item self-reported questionnaire. The PSS measures the frequency of the individual's feelings and thoughts regarding events perceived as stressful within the past month. ${ }^{[19]}$ The 10 -item PSS has a reliability rating ranging from 0.829 to 0.903 among groups. Response choices uses a five-point Likert scale to rate the item. The respondent's choices range from $0=$ Never to $4=$ Very Often . The final score is obtained by a tally of all scores ranging from 0 to 40 with higher scores indicating higher perceived stress. ${ }^{[19,20]}$

Resilience was measured using The Connor-Davidson Resilience Scale (CD-RISC), created to address aspects of resilience and for use in clinical practice. ${ }^{[21]}$ The abridged CD-RISC-10 version reflects the ability to tolerate experiences such as change, personal problems, illness, pressure, failure and painful feeling. The scale uses a five point Likert scale ranging from 0-4: not true at all (0), rarely true (1), sometimes true (2), often true (3), and true nearly all of the time (4). Total scores (0-40) can be obtained by summing all responses, with higher scores reflecting greater resilience. The reliability rating ranged from in different $.85-.95 .{ }^{[21]}$

The questionnaire included basic demographic profile: age, gender and current level of education. At the end of the survey, the participants were asked three open ended questions: identify the main stressor/s they currently faced, coping strategies they have utilized that have been effective in helping them cope with stress and whether their coping strategies have changed in past month.

\subsection{Data analyses}

The survey analyses were completed using Statistical Package for Social Sciences (SPSS) Version 25. Descriptive analysis was used for the demographic variables and to determine the mean score of the survey instruments. T-test and Pearson's correlation were used to determine relationships between variables.
The qualitative data were analyzed using the six steps developed by Braun and Clarke, ${ }^{[22]}$ which include familiarizing, assigning codes, searching for patterns or themes, reviewing themes, defining themes, and reporting. A member of the team read and re-read several times to ensure familiarity with the content. The data was organized in a more meaningful way using open coding to help identify the common threads and meanings that occurred. Patterns of meaning and emerging themes were identified. Subsequently, another team member reviewed the identified themes and the corresponding quotes. The team discussed the results. The final identified themes were determined.

\section{RESUltS}

\subsection{Quantitative data}

\subsubsection{Sample characteristics}

The total sample $(\mathrm{N}=147)$ consisted of $101(69 \%)$ undergraduate nursing students and $46(31 \%)$ graduate nursing students. The participants were mostly female (78\%). The total mean age of the participants was 28.53 (range $=18$ 56), undergraduate students mean age was 23 (range $=18$ - 28) and graduate students mean age was 38.31 (range = 28 - 56). Majority of the participants identified their race as White (40.7\%), followed by Asian (21.3\%), Black (18.7\%), Mixed (10.7\%), Pacific Islander (4.7\%) and non-disclosed $(2 \%)$.

\subsubsection{Perceived stress level}

The participants completed the PSS to measure their perception of stress level within the past month. The total mean PSS score was $32.1(\mathrm{SD}=7.1)$. The mean PSS score for the undergraduate students was $33.2(\mathrm{SD}=7.26)$ and the mean PSS score for graduate students was 30.46 (SD = 6.78). An independent samples $t$-test comparing the PSS mean between the undergraduate nursing students and graduate nursing students found a significant difference between the means of the two groups $(\mathrm{t}(145)=2.041, p<.05)$. The undergraduate nursing students had a significantly higher perceived level of stress compared to the graduate nursing students.

\subsubsection{Resilience Level}

The participants completed the CDC-RISC to measure resilience. The total CDC-RISC mean score was 38.1 ( $\mathrm{SD}=$ 5.95). The mean CDC-RISC score for the undergraduate was $36.87(\mathrm{SD}=5.97)$ and the mean score for the graduate nursing students was $40.56(\mathrm{SD}=4.81)$. An independent samples t-test comparing the CDC-RISC score mean between the undergraduate nursing students and graduate nursing students found a significant difference between the means of the two groups, $(\mathrm{t}(145)=-3.770, p=.000)$. The undergraduate nursing students had a significantly lower resilience level compared to the graduate nursing students. 


\subsubsection{Correlation between perceived stress, resilience and} demographic factors

Correlations between perceived stress level, resilience level and demographic factors were investigated. A negative correlation was found between perceived stress level and resilience level, $(r=-.423, p=.000)$, indicating participants with higher resilience level had lower perceived stress level. Age was found to be significantly correlated with both perceived stress and resilience level. A negative correlation was found between age and perceived stress $(\mathrm{r}=-.298, p=.000)$, those who were younger had a higher perceived stress level. A positive correlation was found between age and resilience level $(\mathrm{r}=.263, p=.001)$, those who were older had a higher resilience level. There was no significant correlation found between perceived stress and resilience level and gender and race.

\subsection{Qualitative data: Thematic analyses}

Following data analysis two major themes were identified with associated subthemes:

- Current stressors: Subthemes: i) health of self and others', ii) academic and financial uncertainty, iii) and strain of isolation on relationships were common among both groups.

- Coping strategies: Subthemes i) what was and ii) what is now.

\subsubsection{Current stressors}

\section{Health: Health of self and others}

The primary concern for all groups was health, specifically the health of themselves and their families. The undergraduate students were fearful for their parents, while the graduate students were fearful for the health of themselves and their immediate families. An additional health-related stressor for the graduates was that as frontline workers with a considerable increase in hours worked during the global health crises and direct exposure to patients diagnosed with COVID-19, they were placing themselves at risk and secondarily their families. Most graduate students shared a heightened stressor which centered on the increasing number of patients, the severity of illness, and increased death rates related to the pandemic.

\section{Uncertainty: Academic and financial uncertainty}

The common stressor for both groups was uncertainty. The students felt they lacked foresight of what would happen and the impact on their future. The main concerns regarding uncertainty surrounded academic progression and outcomes, and specifically for the graduate students the financial uncertainty. Many graduate students faced reduction in hours for themselves or their significant financially contributing family member including unemployment, and were concerned of the impact. Financial stress also extended to the final year under- graduate nursing students as they feared the reduced clinical exposure during this critical time in their education would negatively impact employability upon graduation. Freshmen up to and including junior undergraduate students were more concerned about academic progression and the ability to be successful in their current courses; given the sudden change in their learning platform, prohibited clinical attendance, and the lack of access to face-to-face academic support.

Relationships: Strain of isolation on family and social relationships

Relationships were important to both graduate and undergraduate students. In fact, pre-pandemic coping mechanisms often reflected the reliance on the support gained through social groups such as family or close friends. The physical and social isolation that resulted from the pandemic either forced isolation from these support groups or forced constant togetherness, which for some students this unfamiliar and unusual situation became an additional source of stress.

\subsubsection{Coping strategies}

What was: When faced with stress of this magnitude individuals resort to their preferred or usual methods of coping. The identified pre-pandemic coping strategies included physical activity - specifically exercising at the gym, social interaction with friends or family, and social activities - specifically attending church, sporting events, and celebratory group activities. The stress faced in this instance and the loss of normalcy impacted the strategies most of the respondents utilized in past stressful situations.

What is now: As a result of the pandemic, social gatherings were restricted and physical distancing guidelines were imposed. Individuals were faced with abandoning or amending previously held coping strategies, or choosing new and innovative ways of handling their stress and maintaining some aspect of normalcy. For $36 \%$ of the total respondents their coping strategies changed as their most helpful strategies to alleviate stress pre-pandemic were inaccessible. The main reasons cited for this shift were related to the isolation and inaccessibility of the gym, lack of contact and social support from family and friends, and lack of physical access to there place of worship. Respondents identified coping strategies were replaced by an increased or renewed reliance on faith (prayer and meditation), investment in self-care, trying new things - including new hobbies, journaling, and modifying exercises to those that could be completed at home. Of the graduate students, $24 \%$ voiced difficulty in replacing or amending their coping strategies, while $40 \%$ of the undergraduate students voiced difficulty in coping with the changes as a direct result of their response to stress and the imposed restrictions. 


\section{Discussion}

Nursing students have been confronted with challenges due to the abrupt change of the learning platform, inability to have clinical experience and other difficulties resulting from the COVID-19 pandemic. The aim of the study was to determine the perceived stress level, resilience level, stressors and coping strategies of nursing students in the undergraduate and graduate nursing program.

The results of the study indicate that the perceived stress level of nursing students' is high $(\mathrm{m}=32.1, \mathrm{SD}=7.1)$ compared to the normative data published by the author of the instrument $(\mathrm{m}=13.02, \mathrm{SD}=6.35){ }^{[20]}$ This finding is similar to the findings of other studies which indicated students having higher stress levels due to the COVID-19 pandemic. ${ }^{[12,23,24]}$ Both groups of students identified common stressors including: concerns for the health of themselves and their loved ones, lack of social support and social isolation, academic progression and success, finances, and inaccessible coping mechanisms. Despite the additional concerns among the graduate students regarding the increased patient mortality and their own safety, the study found graduate nursing students to have a lower level of perceived stress and higher resilience when compared to the undergraduate nursing student.

In addition, the findings suggest that those who were older had lower stress and higher resilience. This corresponds to research that suggests age and or maturity might be a factor that contributes to greater resilience and younger students express lower resilience in nursing than older students. ${ }^{[25,26]}$ Southwick et al. ${ }^{[27]}$ however, posited that resilience occurs on a continuum and is not always consistent, but reliant on situational factors and development. This was indicated in this study, as most participants opined, they previously had great coping skills but now were experiencing difficulty adjusting to the stressful consequences of the pandemic.

The main sources of stress were similar to those identified in the literature: academics, clinical placement and performance, finances, and job security. ${ }^{[2,7-9]}$ The significant difference with the current study being health-related concerns, a direct result of the pandemic. Coping strategies in place prior to the pandemic were similar across both groups. Despite experiencing additional stressors related to the global health crises, the graduate students had less difficulty incorporating and transitioning to more accessible and alternate coping strategies.

Similar to all students, nursing students face multiple stressors, both personal and academic. However, the undergraduate nursing student is more vulnerable to unique stressors in their training related to the clinical environment, clinical expectations, performance and patient decline. ${ }^{[28]}$ Psychological and emotional stressors are a prominent occurrence in the profession. Therefore, the ability to demonstrate resilience and safely contend with these stressors and adapting to these stressful situations impacts their future performance and professional practice.

Resilience is highly individualized, demonstrated in multiple ways, and develops in response to a stressor, hardship or adversity. ${ }^{[7]}$ The transition to a complete virtual learning platform in the Spring 2020 semester for nursing students in both the graduate and undergraduate programs was unexpected and unfamiliar. Both groups of students encountered similar stressors. However, distinctly different responses were seen between the graduate and undergraduate students regarding their perceived stress and resilience level following this shared experience. Based on the responses, we attribute this to two variables: age and experience. The graduate students were older and had more exposure to life and clinical experiences which allowed them to be more adaptable to life altering situations. This is supported by literature that propose resilience as a learned behavior in response to previously experienced adversity. ${ }^{[13,29]}$

\section{Recommendations}

Resilience implies a situation can be reframed to be a useful teaching experience; ${ }^{[30]}$ and results in a successful adaptation to the adversarial experience or significant stressor. ${ }^{[29]}$ For nurse educators, there is the responsibility to prepare students academically, but also an opportunity to assist students at both levels in strengthening their resilience. In doing so we provide students with the skill set to face crises and challenges in their professional lives. ${ }^{[30]}$

Nurse educators can promote the development of resilience through their interaction, promoting of decision making, and identifying resources for personal and emotional development. ${ }^{[28,31]}$ Kirsten et al., ${ }^{[30]}$ adds that developing resilience also involves the students' response to the patient in a stressful situation or crises. For the undergraduate students who demonstrated less resilience, the nurse educator can use stressful events in the clinical area to teach the students problem solving, and development of resilient characteristics such as coping with their emotions. Efforts integrated at this level has the capability to influence resilience in other aspects of their lives. ${ }^{[27]}$

Nurse educators are well placed to support both graduate and undergraduate students in developing strategies to cope with academic and clinical stressors, and or stressful events that impact their academic life. ${ }^{[9]}$ Educators can implement strategies to develop and strengthen the resilience of nursing 
students through role modeling, ${ }^{[31]}$ having dialogue emphasizing healthy coping strategies, and providing resources for students to utilize during stressful situations. Southwick et al. ${ }^{[27]}$ suggests support for development of resilience can occur before, during, and following exposure to a stressor. Providing this level of support promotes the student's ability to develop resilience demonstrated through a positive adaptation to their circumstance, and promotion of wellbeing in preparation for future challenges. More qualitative studies are needed to capture the experience of stress and resilience from the students' perspective.

\section{Limitation}

The main limitation was that this study was undertaken at only one tertiary institution within New Jersey, which affects the generalizability of the findings. However, as this event affected students on a national level this study could potentially be replicated at other tertiary institutions within the United States. An additional limitation is the individual factors associated with resilience, specifically each individual's capacity to respond to stressors and support afforded to them, which differs for each person.

\section{Conclusion}

Regardless of the educational level, having faced the same adversarial event, nursing students perceived the COVID-19 pandemic as a significant stressor and experienced similar effects during this global event. The results suggested the graduate students demonstrated less perceived stress and higher resilience in the face of the COVID-19 pandemic. Undergraduates identified academic progression and outcomes as their main stressors while graduate students found the financial uncertainty, family health and economic stability as more stressful concerns; which may be attributable to age and experience. The findings of this study identify a need to develop strategies to promote and develop undergraduate nursing student resilience to assist with coping with adversities in their personal and professional lives in the future.

\section{CONFLICTS OF INTEREST Disclosure}

The authors declare that there is no conflict of interest.

\section{REFERENCES}

[1] Selye H. Stress and distress. Comprehensive Therapy. 1975; 1(8): 9-13.

[2] McCarthy B, Trace A, O'Donovan M, et al. Nursing and midwifery students' stress and coping during their undergraduate education programmes: An integrative review. Nurse Education Today. 2018; 61: 197-209. PMid:29227889 https://doi.org/10.1016/j.ne dt.2017.11.029

[3] Boulton M, O'Connell KA. Nursing students' perceived faculty support, stress, and substance misuse. Journal of Nursing Education. 2017; 56(7): 404-411. PMid:28662256 https://doi.org/10.3 928/01484834-20170619-04

[4] Persson PB, Zakrisson A. Stress. Acta Physiologica. 2016; 216(2): 149-152. PMid:26666386 https://doi.org/10.1111/apha.1 2641

[5] Bartlett ML, Taylor H, Nelson JD. Comparison of mental health characteristics and stress between baccalaureate nursing students and nonnursing students. Journal of Nursing Education. 2016; 55(2): 87-90. PMid:26814818 https://doi.org/10.3928/01484834-20160 114-05

[6] Jimenez C, Navia-Osorio P, Diaz C. Stress and health in novice and experienced nursing students. Journal of Advanced Nursing. 2010; 66(2): 442-455. PMid:20423427 https://doi.org/10.1111/j. $1365-2648.2009 .05183 . x$

[7] Thomas LJ, Asselin M. Promoting resilience among nursing students in clinical education. Nurse Education in Practice. 2018; 28: 231-234. PMid:29128734 https://doi.org/10.1016/j.nepr.2017.10 .001

[8] Mahfouz R, Alsahli H. Perceived stress and coping strategies among new nurse students in clinical practice. Journal of Education and Practice. 2016; 7(23): 118-128.
[9] Watson D, Monson K, Marshall B. Working on nursing students' resilience. Kai Tiaki: Nursing New Zealand. 2019; 25(1): 14-16. https://doi.org/10.1007/s41193-019-0086-0

[10] Thomas-Davis A, Bullock AP, Hooper H, et al. The effects of stress on first-year graduate students in health professions. Journal of the National Society of Allied Health. 2020; 17(1).

[11] Stillwell SB, Vermeesch AL, Scott JG. Interventions to reduce perceived stress among graduate students: A systematic review with implications for evidence-based practice. Worldviews on EvidenceBased Nursing. 2017; 14(6): 507-513. PMid:28795775 https: //doi.org/10.1111/wvn.12250

[12] Cao W, Fang Z, Hou G, et al. The psychological impact of the COVID-19 epidemic on college students in China. Psychiatry Research. 2020; 287: 112934. PMid:32229390 https ://doi .org/10 $.1016 / j \cdot$ psychres .2020 .112934

[13] Herrman H, Stewart DE, Diaz-Granados N. et al. What is Resilience? The Canadian Journal of Psychiatry. 2011; 56(5): 258-265. PMid:21586191 https://doi.org/10.1177/07067437110560 0504

[14] Bonanno GA. Loss, trauma, and human resilience: Have we underestimated the human capacity to thrive after extremely aversive events? American psychologist. 2004; 59(1): 20. PMid:14736317 https://doi.org/10.1037/0003-066X.59.1.20

[15] Stephens TM. Nursing student resilience: A concept clarification Nursing Forum (Hillsdale). 2013; 48(2): 125-133. PMid:23600641 https://doi.org/10.1111/nuf.12015

[16] Hart PL, Brannan JD, De Chesnay M. Resilience in nurses: An integrative review. Journal of Nursing Management, 2014; 22(6): 720-734.

[17] Rutter M. Psychosocial resilience and protective mechanisms. American Journal of Orthopsychiatry. 1987; 57(3): 316-331. PMid:3303954 https://doi.org/10.1111/j.1939-0025.1987.tb03541.x 
[18] Rose S. Medical student education in the time of COVID-19. Jama. 2020; 323(21): 2131-2132. PMid:32232420 https ://doi .org/10 .1001/jama.2020.5227

[19] Cohen S, Kamarck T, Mermelstein R. A global measure of perceived stress. Journal of Health and Social Behavior. 1983; 385-396.

[20] Cohen S, Williamson G. Perceived stress in a probability sample of the United States. In S. Spacapan \& S. Oskamp (Eds.), The social psychology of health. 1988; 31-67: Sage Publications, Inc.

[21] Connor KM, Davidson JR. Development of a new resilience scale: the Connor-Davidson Resilience Scale (CD-RISC). Depress Anxiety. 2003; 18(2): 76-82. PMid:12964174 https://doi.org/10.100 2/da. 10113

[22] Braun V, Clarke V. Using thematic analysis in psychology. Qualitative Research in Psychology, 2006; 3(2): 77-101. https ://doi.or g/10.1191/1478088706qp063oa

[23] Medina Fernández IA, Carreño Moreno S, Chaparro Díaz L, et al. Fear, Stress, and Knowledge regarding COVID-19 in Nursing Students and Recent Graduates in Mexico. Invest Educ Enferm. 2021 Feb; 39(1): e05. PMid:33687809 https : //doi.org/10.17533/u dea.iee.v39n1e05

[24] Son C, Hegde S, Smith A, et al. Effects of COVID-19 on College Students' Mental Health in the United States: Interview Survey Study. J Med Internet Res. 2020; Sep 3; 22(9): e21279. PMid:32805704 https://doi.org/10.2196/21279

[25] Meyer G, Shatto B. Resilience and transition to practice in Direct Entry nursing graduates. Nurse Educ Pract. 2018 Jan; 28: 276-279.
PMid:29042183 https://doi.org/10.1016/j.nepr. 2017.10 .008

[26] Pitt V, Powis D, Levett-Jones T, et al. The influence of personal qualities on performance and progression in a pre-registration nursing programme. Nurse Education Today. 2014; 34: 866-871. PMid:24231636 https ://doi.org/10.1016/j.nedt. 2013.10 .011

[27] Southwick SM, Bonanno GA, Masten AS. et al. Resilience definitions, theory, and challenges: interdisciplinary perspectives. Eur J Psychotraumatol. 2014; Oct 1; 5. PMid:25317257 https://doi. org/10.3402/ejpt.v5.25338

[28] Reyes AT, Andrusyszyn M, Iwasiw C. et al. Resilience in nursing education: An integrative review. Journal of Nursing Education. 2015; 54(8): 438-444. PMid:26230163 https ://doi.org/10.3928/01 484834-20150717-03

[29] Ran L, Wang W, Ai M. et al. Psychological resilience, depression, anxiety, and somatization symptoms in response to COVID19: A study of the general population in China at the peak of its epidemic. Soc Sci Med. 2020 Oct; 262: 113261. PMid:32758794 https://doi.org/10.1016/j.socscimed.2020.113261

[30] Kirsten EA, Lyberg A, Severinsson E. Development of resilience in nursing students: A systematic qualitative review and thematic synthesis. Nurse Education in Practice. 2019; 41.

[31] Froneman K, du Plessis E, Koen MP. Effective educator-student relationships in nursing education to strengthen nursing students' resilience. Curationi. 2016; 39(1): 1-9. 